\title{
A Hybrid Approach to Estimating the Efficiency of Public Spending on Education in Emerging and Developing Economies
}

\author{
Francesco Grigoli ${ }^{1}$ \\ ${ }^{1}$ International Monetary Fund, Washington DC, USA \\ Correspondence: Francesco Grigoli, International Monetary Fund, 700 19th Street NW, Washington DC 20431, USA
}

Received: October 8, 2014

Accepted: October 31, 2014

Available online: December 11, 2014

doi:10.11114/aef.v2i1.609

URL: http://dx.doi.org/10.11114/aef.v2i1.609

\begin{abstract}
The measurement of the efficiency of public education expenditure using parametric and non-parametric methods has proven challenging. This paper seeks to overcome the difficulties of earlier studies by using a hybrid approach to measure the efficiency of secondary education spending in emerging and developing economies. The approach accounts for the impact of the level of development on education outcomes by constructing different efficiency frontiers for lower- and higher-income economies. We find evidence of large potential gains in enrollment rates by improving efficiency. These are largest in lower-income economies, especially in Africa. Reallocating expenditure to reduce student-to-teacher ratios and improving the quality of institutions could help improve the efficiency of education spending. Easing the access to education facilities and reducing income inequality could also help improve efficiency.
\end{abstract}

Keywords: education expenditure, efficiency, hybrid, developing economies, emerging economies

\section{Introduction}

Measuring the efficiency of education spending in emerging and developing economies has been a thorny challenge for researchers. Commonly used techniques, such as Data Envelopment Analysis (DEA) and Stochastic Frontier Analysis (SFA), have proven problematic for different reasons. Under DEA and other non-parametric techniques, for example, it is difficult to incorporate a large number of explanatory variables. Studies using these techniques have typically related public education spending, as a single input, to educational outcomes. This approach, however, neglects the effect of exogenous factors (such as the level of economic development) on educational outcomes. If these other factors also affect educational outcomes, a single input DEA will produce biased efficiency scores. Non-parametric techniques also assume there is no measurement error in the relationship between inputs and outputs. On the other hand, under SFA and other regression-based approaches it is possible to incorporate a larger number of inputs and to control for stochastic influences. In practice, however, it has been difficult to apply these approaches, because of the statistically insignificant relationship between spending (and other inputs) and outcomes.

This paper contributes to the literature by adopting a modified version of the hybrid approach developed by Wagstaff and Wang (2011) that helps address the weaknesses of both DEA and SFA, and providing a more refined measure of education spending efficiency. In particular, this approach is used to compute the efficiency of secondary education public expenditure for emerging and developing economies and the associated potential gains in net enrollment rates that could be achieved by eliminating inefficiencies. This innovative method does not require any assumption about the distribution of the efficiency scores and allows for multiple efficient observations. At the same time, it takes into account statistical noise as in SFA and thus helps address measurement error. In addition, the hybrid approach computes an efficiency score on the basis of actual observations on the efficiency frontier, rather than hypothetical ones. It allows for exogenous constraints, such as the level of development, by constructing different frontiers for different groups. This paper splits the sample into lower- and higher-income groups and constructs group-specific efficiency frontiers.

Consistent with the literature, we find evidence that secondary education expenditure is inefficient in many emerging and developing economies, especially in Africa. The results suggest that at current spending levels, economies in the lower-income group could improve their net enrollment rate, on average, by 36 percentage points, which compares to 7 percentage points in higher-income economies. We also find that a higher student-to-teacher ratio and a higher share of rural population are associated with greater inefficiency in public education spending. The results suggest that policies aimed at reallocating expenditure to reduce student/teacher ratios (where these are high), improving the quality 
of institutions, easing the access to education facilities, and reducing income inequality can help improve the efficiency of education spending.

The remainder of this paper is structured as follows. Section 2 analyzes in detail the issues faced in the literature in measuring the efficiency of education spending in emerging and developing economies. Section 3 shows some descriptive statistics on the education sector, discusses the hybrid approach, presents the results, and assesses their robustness. Section 4 concludes the paper.

\section{A Selective Review of the Research Assessing Education Spending Efficiency}

Efforts to date to assess the efficiency of public education expenditure for emerging and developing economies have been largely limited to the application of non-parametric techniques. Gupta and Verhoeven (2001) employ the Free Disposal Hull (FDH) technique to estimate the efficiency of government expenditure in health and education. They assess the education sector's performance by taking expenditure in purchasing power parity (PPP) terms as an input and gross enrollment rates in primary and secondary schools as outputs. The authors note that adding GDP per capita lowers or cancels the significance of the impact of expenditure on educational output. They argue that the high collinearity of GDP per capita with the expenditure variables is a critical problem, and address the issue by splitting the sample by level of development. They conclude that African countries are less efficient than countries in Asia and in the Western Hemisphere, even though there is wide variation within the region.

Herrera and Pang (2005) work with a sample of 140 developing countries over 1996-2002 to estimate the efficiency of public expenditure in health and education. For education, they use public expenditure as an input and gross primary enrollment and completion rates as outputs. The authors note the positive relationship between expenditure and the level of economic development and suggest that it can be explained by the Balassa-Samuelson effect, according to which price levels in wealthier countries tend to be higher than those in poorer countries. Since this applies to both final goods and factor prices, the price of education will be higher in the country with higher GDP per capita. This is especially the case for nontradable goods and services (such as most education services). As in Gupta and Verhoeven (2001), they divide the sample to address the impact of the level of development on the efficiency of education expenditure. As a second strategy, they also calculate the orthogonal component from a regression between education public expenditure and GDP per capita and introduce it as an input in the DEA. Using this approach, they find that rich countries tend to be in the less efficient group. They identify urbanization as a factor associated with higher efficiency, while the level of expenditure, the government wage bill as a ratio of total expenditure, and income inequality are negatively correlated with efficiency.

Gupta et al. (2007) use DEA on a sample of 50 low-income countries to evaluate the efficiency of education and health expenditure. For education, the authors take public expenditure on education in PPP terms as an input and primary net enrollment and youth literacy rates as outputs. No effort is made to control for the level of development, but the authors acknowledge the need to interpret the results with caution since the output variables are likely to be influenced by factors other than spending. They find no clear relationship between income per capita and the efficiency of education spending. The performance of poor countries varies widely, depending on the output indicator.

One of the few applications of parametric methods can be found in Jayasuriya and Wodon (2003) that use SFA to estimate health and education efficiency frontiers for a sample of 76 countries for the period 1990-98. The authors take the primary enrollment rate as the output variable and real GDP per capita, adult illiteracy, and education expenditure per capita (private and public) as input variables. They also control for changes over time and differences across regions by adding a time trend and regional dummies. The findings suggest that neither education expenditure nor regional differences have a statistically significant impact on net primary enrollment. A second step analysis reveals that efficiency is associated with urbanization and bureaucratic quality.

Greene (2005) uses Herrera and Pang's dataset to estimate health and education efficiency with SFA. For education, primary and secondary school enrollment rates (gross and net), youth literacy rates, primary and secondary completion rates, and average years of schooling are used as dependent variables. Education spending and teachers per student are the independent variables. Adult literacy rates and aid revenue are included as controls. The author shows that fitting SFA models is problematic. First, he attempts the estimation of a panel model for primary and secondary school enrollment rates, but this returns implausible coefficients. Second, following Herrera and Pang, the author takes the 1975-95 and 1996-2002 averages and estimates a two-period panel assuming a normal-truncated normal distribution. The regression coefficients are better behaved and the author finds that the most relevant determinant of student educational outcomes is the adult literacy rate, followed by the teacher-to-student ratio. However, expenditure is not significant and in some cases takes a negative sign. 


\section{Empirical Analysis}

\subsection{An Overview of the Education Sector}

Emerging and developing economies are very different from advanced ones with respect to education spending and outcomes (see Table 1). 1 Education absorbs resources of about $4 \frac{1}{2}$ percent of GDP in emerging and developing countries, about 1 percentage point less than in advanced economies. However, since these economies generally have smaller governments, education expenditure accounts for $16^{1 / 2}$ percent of general government expenditure, $3 \frac{1}{2}$ percentage points more than in advanced economies. In percent of GDP, emerging and developing economies spend relatively more on primary education, while advanced economies spend more on secondary education. However, when measured in PPP per capita terms, advanced economies spend about five times more than emerging and developing ones on both primary and secondary education.

Unsurprisingly, outcome indicators are less favorable in the emerging and developing economies. Net secondary enrollment rates, for example, are about 30 percentage points lower, while adult literacy rates lag behind those in advanced economies by 20 percentage points. Student-to-teacher ratios are substantially higher in emerging and developing economies.

There are also differences in economic and social conditions that can influence educational outcomes. For example, emerging and developing countries are likely to experience more difficulties in accessing education facilities as rural areas are more populated than in advanced economies and this is also reflected in a lower population density. Also, income per capita in the emerging and developing economies is about $1 / 4$ of that in the advanced economies, income distribution is considerably more unequal, and the quality of governance is lower.

\subsection{The Hybrid Methodology}

Wagstaff and Wang (2011) introduce the hybrid approach. In their study, the authors calculate a hybrid frontier using data for education and health. On education, two analyses are carried out for illustrative purposes. The first uses school-level data in California, and the second uses data from the OECD's Program for International Student Assessment (PISA) to evaluate the efficiency of national education systems. However, the paper only aims at showing how the hybrid technique works and no interpretation of the results is proposed.

We describe here the application of the hybrid approach to analyze public expenditure efficiency in secondary education for emerging and developing economies, and highlight how this technique deals with the issues faced by previous studies. Since the policy challenge for the countries in the sample is on improving outcomes (rather than reducing spending), we modify the original version of the technique to measure output-based efficiency. In other words, we focus on estimating inefficiency in terms of how much additional output could be achieved at current levels of spending.

We build a panel dataset of 89 emerging and developing economies over the 2000-10 period and focus on secondary education. The dataset consists of 310 country-year observations. We assume that country $i$ at time $t$ uses an input (i.e., public expenditure per student on secondary education in PPP terms) to produce an output (i.e., secondary enrollment rate) at a certain cost. While it would be preferable to have an indicator that measures the transfer of knowledge (e.g., test scores, such as PISA scores), these data are not available for most of the sample under consideration. Thus, we use net enrollment rates, which are calculated by adjusting the gross enrollment rate for the number of students that are above the normal age for that grade. Arguably, this is a better measure of output than the gross enrollment rate, as the latter can be inflated by a high share of students that need to repeat one or more grades because they are not ready to move to the next level. The cutoff dates of the dataset are determined on the basis of data availability. In particular, data on secondary net enrollment rates are not widely available before 2000. Figure 1 presents a scatter plot of spending per student and the secondary school net enrollment rate, which provides an intuitive sense of how our measure of spending input is correlated with educational output.

The first stage of the method resembles the DEA as it consists of an envelopment process. Under the hybrid method is dubbed "grid search," which identifies the efficient observations. These are defined as those having the highest net enrollment for each level of expenditure per student. However, since more than one data point may have the same level of net enrollment, we define a caliper of size $c$ that is moved along the $x$ axis in steps of size $s$, with $\mathrm{s}$ and $c$ equal to 10 , or 0.1 of the standard deviation of the output variable. ${ }^{2}$ Thus, for every "expenditure per student" range, we identify the data point with the highest net enrollment and mark it as efficient as shown in Figure 2. Table 2 summarizes the findings of the grid search. Out of the 310 data points available, only 42, or 14 percent, are labeled as efficient.

\footnotetext{
${ }^{1}$ The IMF country classification is adopted here (for more details see http://www.imf.org/external/pubs/ft/weo/2013/01/weodata/weoselagr.aspx).

${ }^{2}$ Note that $s$ has to be less or equal to $c$.
} 
Table 1. Selected education and social indicators

\begin{tabular}{|c|c|c|}
\hline & Advanced & $\begin{array}{c}\text { Emerging and } \\
\text { Developing } \\
\end{array}$ \\
\hline \multicolumn{3}{|l|}{ Education expenditure } \\
\hline Public expenditure (in percent of GDP) & 5.4 & 4.5 \\
\hline Public expenditure (in percent of general government expenditure) & 12.9 & 16.4 \\
\hline Public expenditure on primary education (in percent of GDP) & 1.4 & 1.8 \\
\hline Public expenditure on secondary education (in percent of GDP) & 2.2 & 1.6 \\
\hline Public expenditure on primary education (PPP, int. dollars) & 5,894 & 1,101 \\
\hline Public expenditure on secondary education (PPP, int. dollars) & 7,560 & 1,442 \\
\hline \multicolumn{3}{|l|}{ Education indicators } \\
\hline Adult literacy rate (in percent of population over 15) & 97.0 & 79.1 \\
\hline Primary gross enrollment (in percent of primary school age population) & 102.6 & 102.5 \\
\hline Secondary gross enrollment (in percent of secondary school age population) & 106.3 & 67.2 \\
\hline Primary net enrollment (in percent of primary school age population) & 97.4 & 85.3 \\
\hline Secondary net enrollment (in percent of secondary school age population) & 90.7 & 59.9 \\
\hline Primary completion rate (in percent of primary school age population) & 98.7 & 83.4 \\
\hline Population with primary education (in percent of population over 25) & 16.8 & 17.1 \\
\hline Population with secondary education (in percent of population over 25) & 31.9 & 17.9 \\
\hline Student-to-teacher ratio in primary education & 15.3 & 29.6 \\
\hline Student-to-teacher ratio in secondary education & 11.9 & 19.7 \\
\hline \multicolumn{3}{|l|}{ Economic and social indicators } \\
\hline Real GDP per capita (PPP, int. dollars) & 30,837 & 7,409 \\
\hline Rural population (in percent of population) & 23.4 & 51.1 \\
\hline Population density (per square km of land area) & 377.2 & 116.4 \\
\hline Gini coefficient & 29.53 & 41.15 \\
\hline \multicolumn{3}{|l|}{ Governance indicators } \\
\hline WGI political stability (-2.5 to 2.5$)$ & 0.82 & -0.31 \\
\hline WGI voice and accountability (-2.5 to 2.5$)$ & 1.23 & -0.37 \\
\hline WGI government effectiveness ( -2.5 to 2.5 ) & 1.51 & -0.42 \\
\hline CPIA public sector transparency ( 1 to 6 ) & $\ldots$ & 2.87 \\
\hline CPIA public adminis tration quality ( 1 to 6 ) & $\ldots$ & 2.99 \\
\hline
\end{tabular}

Source: Barro-Lee database, World Development Indicators, and World Governance Indicators.

The second stage introduces stochastic features. We apply a locally weighted scatter plot smoothing (LOWESS) through the data points that have been marked as efficient in the first stage. ${ }^{3}$ While this approach does not address omitted variable bias, it helps to address measurement error as it produces a smooth set of values from the scatter plot by running a series of locally weighted regressions. ${ }^{4}$ This is represented in Figure 3, with the stochastic frontier defined in terms of the predicted net enrollment rate for each efficient data point.

The second stage introduces stochastic features. We apply a locally weighted scatter plot smoothing (LOWESS) through the data points that have been marked as efficient in the first stage. ${ }^{5}$ While this approach does not address omitted variable bias, it helps to address measurement error as it produces a smooth set of values from the scatter plot by

\footnotetext{
${ }^{3}$ See Cleveland (1979) for details on LOWESS.

${ }^{4}$ The LOWESS defines a neighborhood for each efficient point (bandwidth) and fits a regression line weighted by the distance of the points in the neighborhood. The frontier is then defined as the predicted net enrollment of each efficient observation.

${ }^{5}$ See Cleveland (1979) for details on LOWESS.
} 
running a series of locally weighted regressions. ${ }^{6}$ This is represented in Figure 3, with the stochastic frontier defined in terms of the predicted net enrollment rate for each efficient data point.

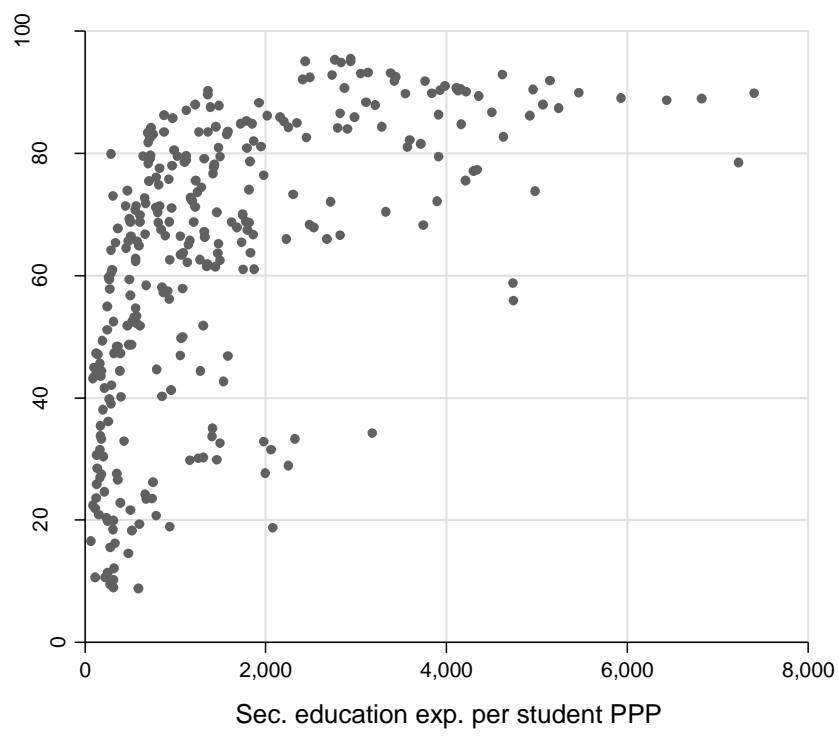

Figure 1. Education input and output

Source: World Development Indicators.

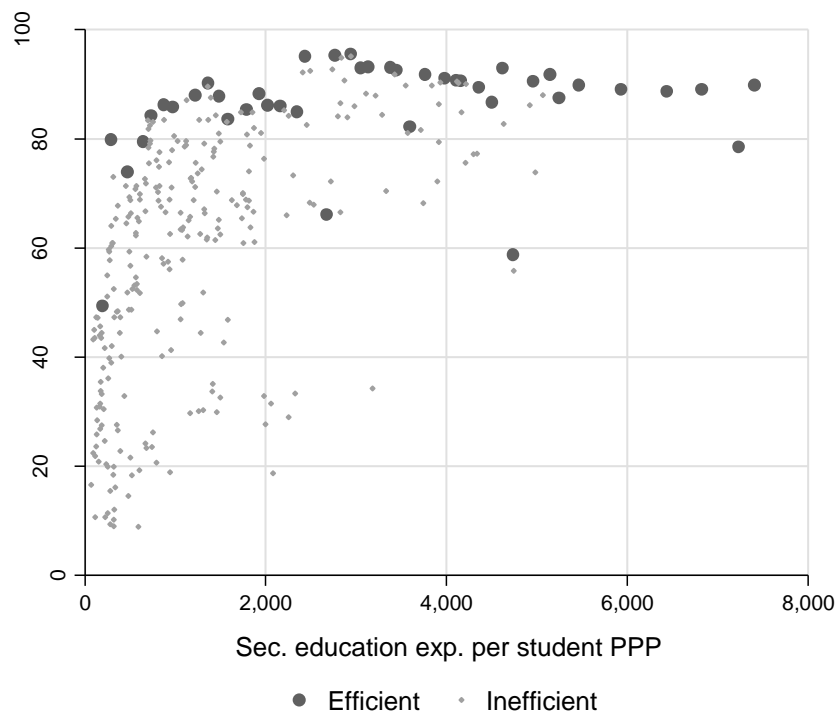

Figure 2. Grid search

Source: Author's calculations.

\footnotetext{
${ }^{6}$ The LOWESS defines a neighborhood for each efficient point (bandwidth) and fits a regression line weighted by the distance of the points in the neighborhood. The frontier is then defined as the predicted net enrollment of each efficient observation.
} 
Table 2. Grid search outcome

\begin{tabular}{lrr}
\hline & Obs. & \multicolumn{2}{c}{ Percent } \\
\hline Efficient & 42 & 13.6 \\
Inefficient & 268 & 86.5 \\
\hline Total & 310 & 100.0 \\
\hline
\end{tabular}

Source: Author's calculations

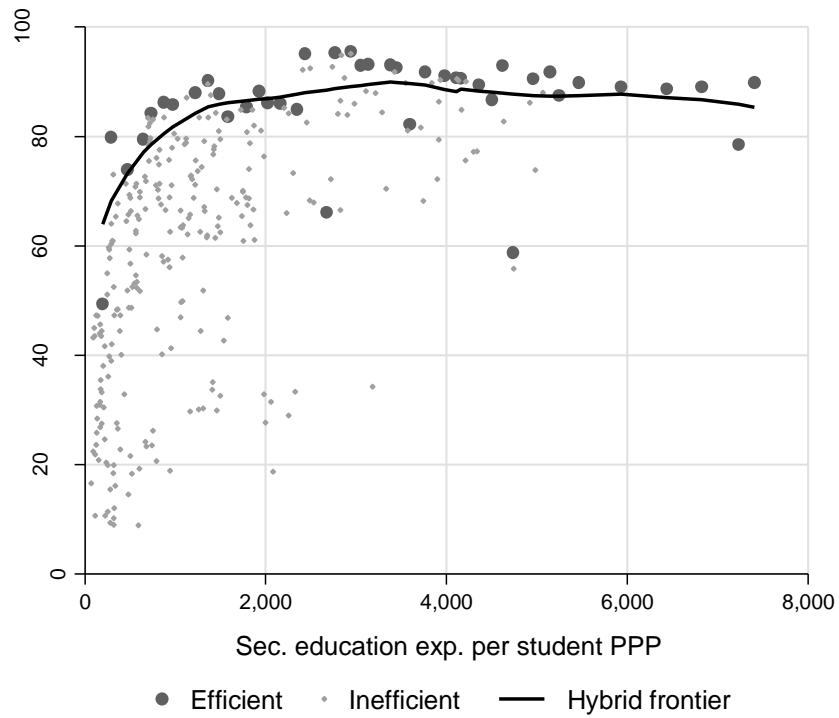

Figure 3. Hybrid frontier

Source: Author's calculations.

Another point to be noted is that the first two stages may leave some observations above the smoothed frontier. This happens because the efficient data points identified in the first stage have their net enrollment replaced by the predicted one in the second stage. For these observations, their inefficiency is set to zero, as it is for observations on the frontier.

In the third stage, we calculate the potential gains by implementing a Mahalanobis matching (see Leuven and Sianesi, 2003 , for further discussion). This allows the match of every data point off the frontier with the closest data point on the frontier. The distance between the inefficient data point and its matched efficient one is expressed in terms of net enrollment rate and represents the output-based measure of inefficiency. The advantage of this procedure is that every data point is matched with a country observation in the dataset that has managed at a certain point in time to produce the highest level of output at a certain cost. This stands in contrast with DEA and SFA, where the inefficiency is calculated as the distance of each inefficient observation from the frontier that includes hypothetical comparators.

In presence of exogenous factors affecting the outcome variable, efficiency scores may be inaccurate. In line with Burgess (2006), Wagstaff and Wang (2011) argue that the inefficiency scores need to take into account "exogenous constraints" (i.e., the level of development), in the moment in which the scores are generated. We address the problem by splitting the sample into two groups corresponding to two income quantiles: a "higher-income" and "lower-income" group. ${ }^{7}$ The average income of the higher-income group (US\$16,269 in PPP terms) is more than five times that of the lower-income group and presents much higher variability. Figure 4 presents the probability distribution of the potential gains for the two income groups calculated with a hybrid frontier for the entire sample. It clearly shows how inefficiency is distributed differently in the two income groups, suggesting the importance of controlling for the level of development.

Figure 5 shows how low- and high-income data points are clustered with respect to the enrollment rate. The low-income data points have a systematically lower enrollment rate at a given level of spending, suggesting that GDP per capita is a critical factor to control for and that there are substantial differences in the education production function across these

\footnotetext{
${ }^{7}$ To classify economies into higher- and lower-income we first calculate the economy's mean of the GDP per capita in PPP terms over the years for which there are observations, and then divide the sample with respect to the $50^{\text {th }}$ percentile (median).
} 
two country groups. Thus, as in Gupta and Verhoeven (2001) and Herrera and Pang (2005), we take this heterogeneity into account by generating a different frontier for each income group. However, unlike these earlier studies, we use the hybrid approach described earlier. Figure 5 shows how the location and the shape of the frontier vary across the two income groups.

\subsection{Results}

We compute the efficiency scores and the associated potential gains by country with respect to the relevant frontier and present the country ranking in Figure 6. Over 2000-10, the average potential gain for the 89 economies in the sample is 23 additional enrolled students for every 100 students (in net terms). This implies that, on average, efficient economies could increase their net enrollment rate by this amount without any additional spending. The country-specific shares of the potential gain to the potential enrollment rate (potential gain plus actual enrollment rate) are then calculated and presented in Table 3. These ratios can be conceptually compared to output-based DEA and SFA scores.

Assessing the efficiency of an observation against its relevant frontier reduces the potential gain of low-income economies and therefore increases the efficiency scores. By splitting the sample and measuring the efficiency against the relative frontier, we find that poorer economies are on average less efficient than richer ones. The results suggest that the average efficiency score for the high-income group is 90 percent (or seven additional enrolled students per every 100 students) compared to 55 percent (or 36 additional enrolled students per every 100 students) of low-income economies. Looking at the results from a regional perspective, European and Western Hemisphere economies populate the first half of the ranking, while African economies are among the least efficient.

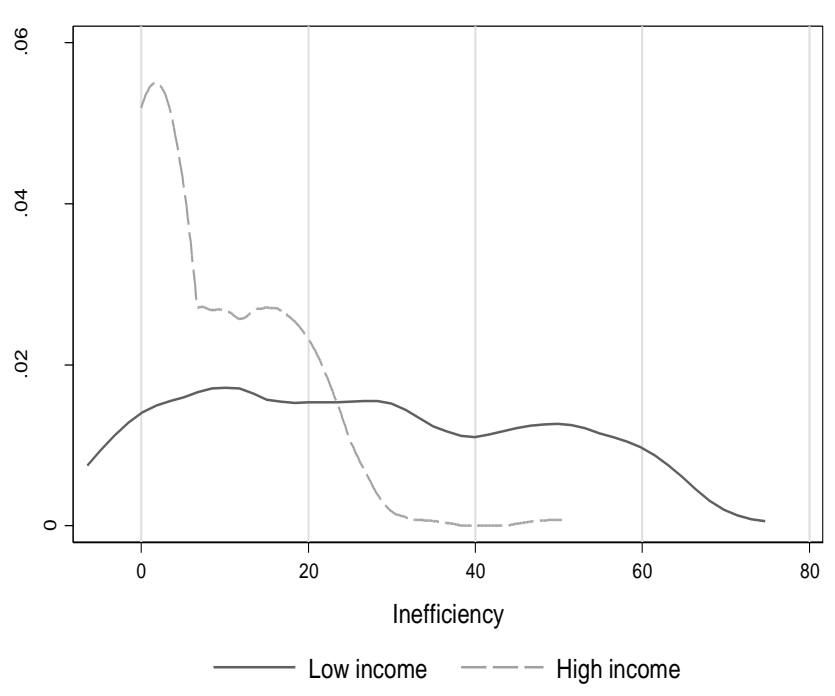

kernel $=$ epanechnikov, bandwidth $=6.4967$

Figure 4. Probability distribution of potential gains

Source: Author's calculations.

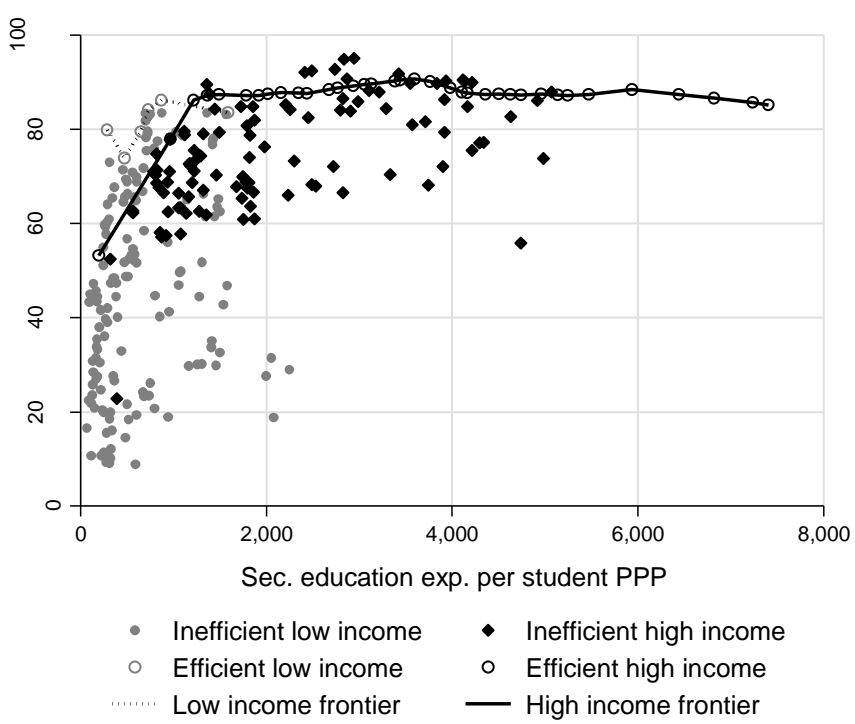

Figure 5. The role of GDP per capita 


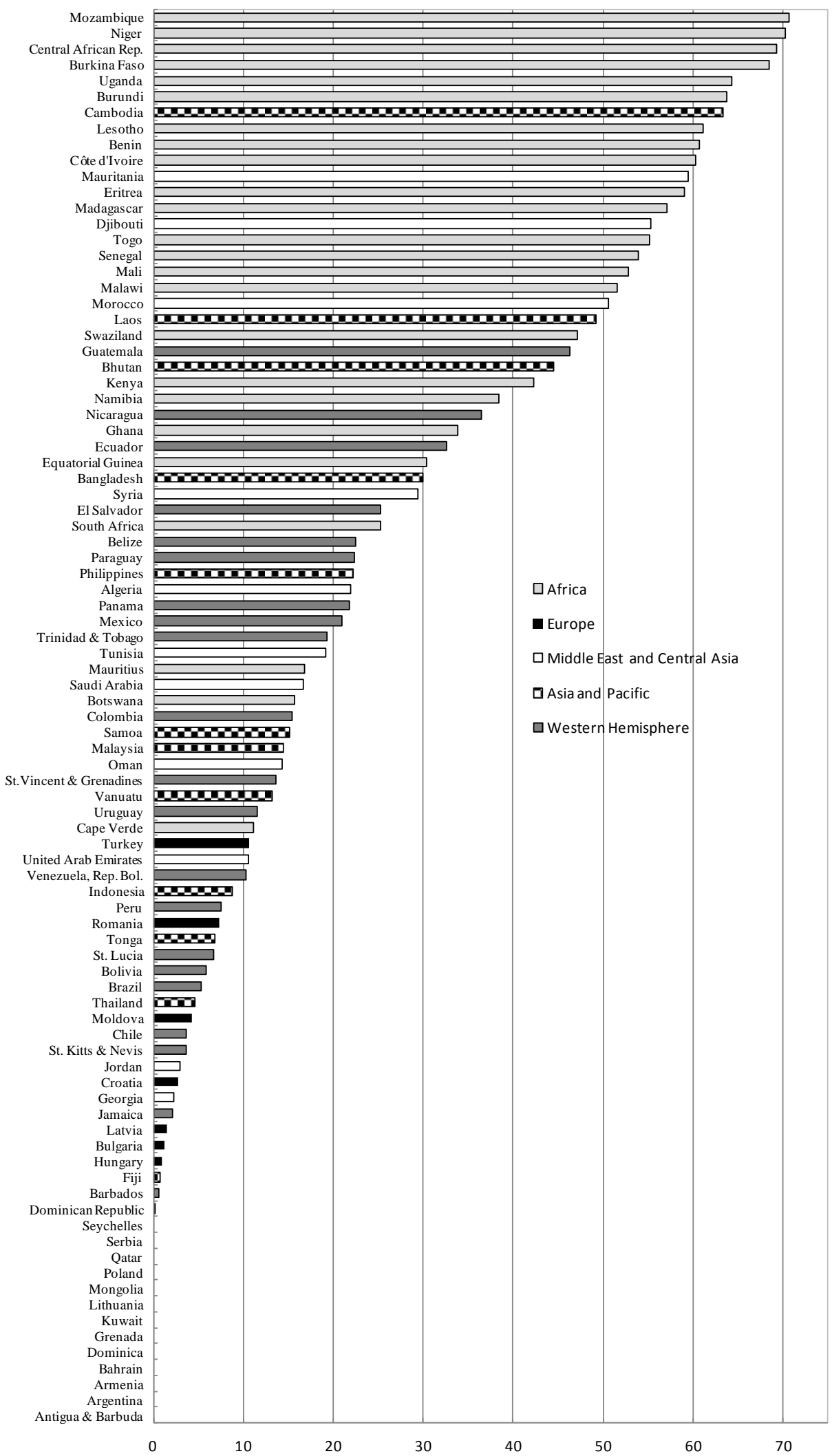

Figure 6. Potential gains (additional enrolled students every 100 students)

Source: Author's calculations. 
Table 3. Efficiency scores

\begin{tabular}{|c|c|c|c|}
\hline Country & Efficiency score & Country & Efficiency score \\
\hline Antigua \& Barbuda & 1.000 & Colombia & 0.802 \\
\hline Argentina & 1.000 & Malaysia & 0.780 \\
\hline Armenia & 1.000 & Trinidad \& Tobago & 0.779 \\
\hline Bahrain & 1.000 & Tunisia & 0.770 \\
\hline Dominica & 1.000 & Mexico & 0.759 \\
\hline Grenada & 1.000 & Panama & 0.747 \\
\hline Kuwait & 1.000 & Algeria & 0.746 \\
\hline Lithuania & 1.000 & Vanuatu & 0.740 \\
\hline Mongolia & 1.000 & Belize & 0.732 \\
\hline Poland & 1.000 & Philippines & 0.723 \\
\hline Qatar & 1.000 & Paraguay & 0.711 \\
\hline Serbia & 1.000 & South Africa & 0.710 \\
\hline Seychelles & 1.000 & El Salvador & 0.665 \\
\hline Dominican Republic & 0.998 & Syria & 0.645 \\
\hline Barbados & 0.992 & Bangladesh & 0.602 \\
\hline Fiji & 0.991 & Ecuador & 0.592 \\
\hline Hungary & 0.989 & Ghana & 0.560 \\
\hline Bulgaria & 0.985 & Namibia & 0.549 \\
\hline Latvia & 0.983 & Nicaragua & 0.543 \\
\hline Jamaica & 0.975 & Kenya & 0.471 \\
\hline Georgia & 0.972 & Bhutan & 0.468 \\
\hline Croatia & 0.969 & Equatorial Guinea & 0.429 \\
\hline Jordan & 0.964 & Guatemala & 0.421 \\
\hline St. Kitts \& Nevis & 0.959 & Morocco & 0.395 \\
\hline Chile & 0.958 & Swaziland & 0.392 \\
\hline Moldova & 0.949 & Laos & 0.384 \\
\hline Thailand & 0.946 & Malawi & 0.355 \\
\hline Brazil & 0.932 & Mali & 0.339 \\
\hline Bolivia & 0.924 & Togo & 0.309 \\
\hline St. Lucia & 0.923 & Djibouti & 0.305 \\
\hline Romania & 0.917 & Madagascar & 0.285 \\
\hline Tonga & 0.914 & Senegal & 0.270 \\
\hline Peru & 0.905 & Lesotho & 0.269 \\
\hline United Arab Emirates & 0.881 & Eritrea & 0.261 \\
\hline Indonesia & 0.880 & Côte d'Ivoire & 0.242 \\
\hline Turkey & 0.876 & Benin & 0.240 \\
\hline Venezuela, Rep. Bol. & 0.868 & Cambodia & 0.207 \\
\hline Cape Verde & 0.855 & Burundi & 0.202 \\
\hline Uruguay & 0.852 & Mauritania & 0.196 \\
\hline St.Vincent \& Grenadines & 0.844 & Uganda & 0.194 \\
\hline Oman & 0.841 & Burkina Faso & 0.143 \\
\hline Botswana & 0.820 & Central African Rep. & 0.133 \\
\hline Saudi Arabia & 0.813 & Niger & 0.120 \\
\hline Samoa & 0.810 & Mozambique & 0.112 \\
\hline Mauritius & 0.806 & & \\
\hline
\end{tabular}

Source: Author's calculations. 


\subsection{Sensitivity Analysis}

Unavoidably, the results are dependent on the size of the caliper and the step set during the first stage. This calls for some robustness checks. We perform a sensitivity analysis of the average inefficiency score and of the country rankings on efficiency by varying $c$ and $s$.

Figure 7 shows in two tri-dimensional charts how the average inefficient spending varies for each combination of $c$ and $s$ for the two income groups, with $c, s=1,2, \ldots, 20$, where 20 corresponds to a 0.2 standard deviation of the output variable. Panels (a) and (b) show that increasing the size of the step and particularly of the caliper causes the size of the average potential gain to rise. This is due to the reduction in the numbers of efficient data points that the smaller calipers and the steps bring about. The surfaces are bumpy and the average potential gain scores drop drastically when the size of the step and the caliper are reduced. This is likely to be due to the reduced sample size.

(A) Low-Income Group

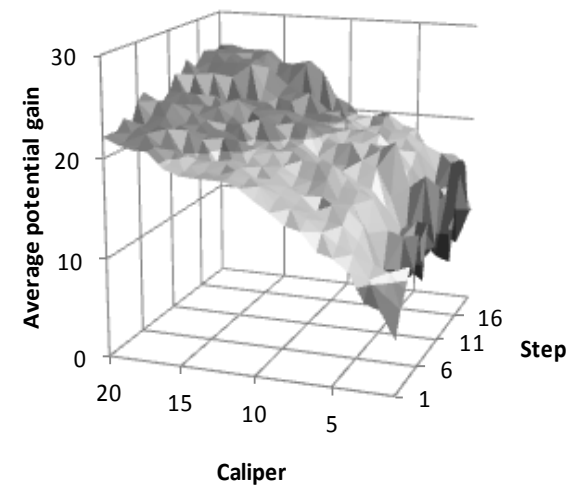

(B) High-Income Group

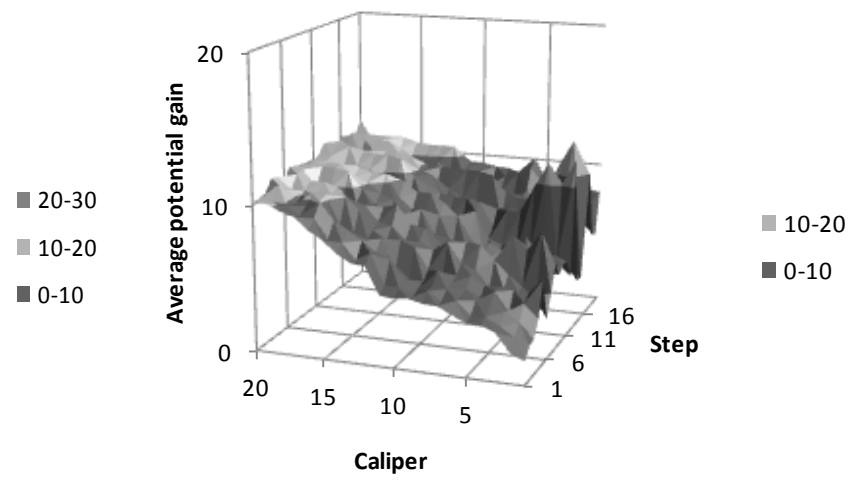

Figure 7. Average Potential Gain

Source: Author's calculations.

Notes: Average potential gain is expressed in additional enrolled students every 100 students. Actual caliper and step used are 1/100 of the values shown. The caliper and step are both defined in terms of standard deviation of the output variable.

We now check how sensitive the rankings are to the combinations of $c$ and $s$. As shown in panel (a) of Figure 8, the surface is relatively flat at around 75 percent of the Spearman rank correlation coefficient. While the size of the correlation coefficient is similar in panel (b), the surface is bumpier and this may be due to the lower number of observations for this group. In general, it can be argued that despite the reduced sample size, the rankings are robust to changes in the size of the caliper and step. Unsurprisingly, the Spearman rank correlation drops when the size of the caliper and step is drastically reduced.

Finally, we check the correlation between the efficiency scores generated by the hybrid model and those of a DEA with the same input and output as in the hybrid model (public expenditure per student on secondary education in PPP terms as input and secondary net enrollment rate as output). The Spearman rank correlation coefficient is 91 percent while the Kendall's tau-b coefficient is 80 percent, and both are statistically significant. ${ }^{8}$ These results imply that the application of the hybrid approach generates some corrections with respect to the DEA ranking.

\subsection{Second-Stage Analysis}

We run a second-stage analysis to assess the determinants of education spending efficiency. Efficiency is represented by the efficiency scores calculated in the first stage, which are a rescaled measure of how much enrollment a country can achieve at current spending levels if it were as efficient as the most efficient country in the sample.

Ideally, any factor that has an impact on the output measure should be taken into account when determining the efficiency scores, i.e. in the first stage (see Burgess, 2006). However, this is not straightforward in the context of the hybrid or non-parametric techniques, and SFA is not an option for the reasons described above. Thus, in line with the literature (see Gupta et al., 2007, and Verhoeven et al., 2007), we perform a correlation analysis and run panel truncated

\footnotetext{
${ }^{8}$ Kendall's tau coefficient is an alternative non-parametric measure of rank correlation. It penalizes dislocations by the distance of the dislocation, rather than the square of the distance as for the Spearman coefficient. The Kendall's tau-b (used in the paper) adjusts for ties.
} 
regressions with fixed effects to identify the factors that account for the variation in the efficiency scores. A multivariate truncated regression framework is warranted as the dependent variable (efficiency scores) is bounded between zero and one.

(A) Low-Income Group

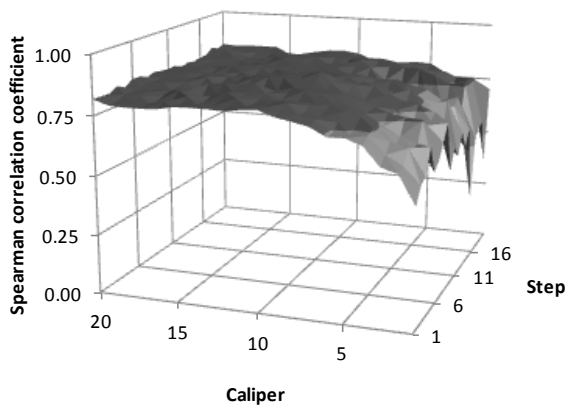

(B) High-Income Group

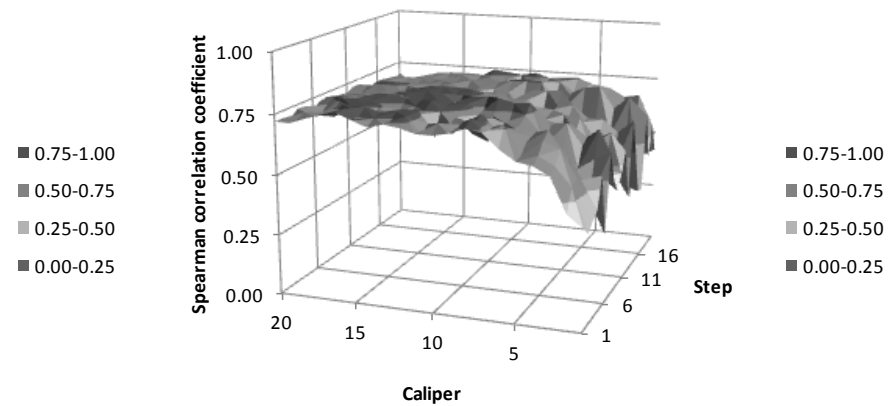

Figure 8. Rank Correlation

Source: Author's calculations.

Notes: Actual caliper and step used are 1/100 of the values shown. The caliper and step are both defined in terms of standard deviation of the output variable.

The variables we test and the expected effects, mostly in line with previous studies (see also Section 2$)^{9}$, are the following:

GDP per capita. This captures the effect of the level of development on enrollment rates within our two country groups (lower income and higher income). ${ }^{10}$ Since we split the sample, we expect the variable to take a positive sign, but if significant, to be of a small magnitude.

Rural population as a share of total population. It may be easier to provide quality inputs, including teachers and reading material, in urban than in rural areas. Similarly, the returns to education may be higher in urban areas because of the closer proximity to jobs which require higher levels of schooling (Jayasuriya and Wodon, 2003, and Herrera and Pang, 2005). Spending may also be less efficient in rural areas because schools are generally further away and transportation systems are not as well developed as in urban regions; this makes it more difficult for students to enroll and attend class. Therefore, we expect a negative effect on education spending efficiency.

Population density. In areas that are less densely populated, students may live far from school and have higher opportunity costs of travel, making it more difficult to enroll. Thus, population density is expected to be positively associated with spending efficiency.

Student-to-teacher ratio. In advanced economies, a higher student-to-teacher ratio is commonly associated with more efficient public education spending. In developing and emerging economies, however, these ratios are often very high and reduce the efficiency of spending. The World Bank (2005) indicates that a number of empirical studies identify an optimal threshold of 25 students per teacher. ${ }^{11}$

The general government wage bill as a share of government spending. Given that education is a labor-intensive activity, the government's labor policies can determine the efficiency with which outputs are delivered (Herrera and Pang, 2005). Moreover, a high wage bill can squeeze out more productive inputs, such as instructional material. Thus, a higher wage bill is expected to be negatively associated with efficiency. Ideally, data on the wage bill in education (as a share of education spending) should be used, but this information is not widely available. Therefore, we use the general

\footnotetext{
${ }^{9}$ Private spending can also influence education outcomes and thus measures of the efficiency of public spending. Data on private spending on secondary education, however, are not widely available in emerging and developing economies.

${ }^{10}$ One could argue that real GDP per capita should not be considered because the hybrid technique already splits the sample in lower- and higherincome countries. However, splitting the sample is similar to having a dummy variable for lower- or higher-income countries. In contrast, a continuous variable has higher information content.

${ }^{11}$ During the period considered, the average student-to-teacher ratio for emerging and developing economies is 20.3, compared to an average of 11.8 students per teacher in advanced economies.
} 
government wage bill as a proxy.

Level of adult literacy. Many studies control for the literacy of adults (Jayasuriya and Wodon, 2003; Herrera and Pang, 2005; and Greene, 2005). More educated parents are likely to attach a higher value to education and have their children enrolled. Similarly, more educated parents tend to have healthier children and early child health is a long-run predictor of other social outcomes, including educational ones (see Almond and Currie, 2010). Hence, we expect a positive effect of this variable on spending efficiency.

Income inequality. For a given level of income, a more equal income distribution (lower Gini coefficient) is expected to have a positive impact on enrollment rates. With a more equal distribution of income, a larger share of the population has sufficient income to attend school and forgo the income that would be generated by participating in the labor market (Herrera and Pang, 2005).

Institutions. Better institutions are associated with higher efficiency of spending (Jayasuriya and Wodon, 2003, and Grigoli and Ley, 2012). We measure the quality of institutions with the "government effectiveness" indicator in the World Bank's Governance Indicators database.

The results from the correlation analysis and the truncated regressions are broadly consistent. Table 4 (on the correlation analysis) suggests that population density, adult literacy, and government effectiveness are positively and significantly associated with the efficiency of education spending, as expected. The general government wage bill (as a share of total spending), as well as the share of the population living in rural areas and income inequality present negative and significant coefficients as expected.

The multivariate framework considerably reduces the number of observations and prevents the inclusion of all regressors in the same equation. The results of Table 5 suggest that population density, adult literacy, and government effectiveness are positively associated with efficiency in education spending, while rural populations and student-to-teacher ratios show a negative and significant coefficient. One noteworthy result is that inequality is bad for efficiency, as a higher Gini coefficient is associated with lower levels of efficiency.

The wage bill is found to be insignificant in the regressions, while the coefficient of real GDP per capita is not statistically different from zero in most of the specifications. The latter suggests that the sample split between higher-income and lower-income economies helps to reduce the bias imposed by income heterogeneity across the sample. As a robustness test, the equations are also estimated with time and regional dummies, as well as on an averaged cross-sectional data. The results are robust to these different specifications.

Table 4. Pair-Wise Correlations with Efficiency Scores

\begin{tabular}{lc}
\hline Real GDP per capita PPP & +++ \\
obs & 310 \\
Population density & + \\
$\quad$ obs & 310 \\
Rural population & --- \\
obs & 310 \\
Student-to-teacher ratio & --- \\
$\quad$ obs & 263 \\
Government effectiveness & +++ \\
$\quad$ obs & 279 \\
Wage bill (percent of total expenditure) & -- \\
obs & 235 \\
Gini coefficient & --- \\
obs & 191 \\
Adult literacy & +++ \\
obs & 72 \\
\hline
\end{tabular}

Source: Author's calculations.

Notes: Triple $+++(---)$ indicates that the efficiency score is positively (negatively) correlated with the associated factor at the 1 percent significance level. Double $++(--)$ indicates that the efficiency score is positively (negatively) correlated with the associated factor at the 5 percent significance level. Single $+(-)$ indicates that the efficiency score is positively (negatively) correlated with the associated factor at the 10 percent significance level. 
Table 5. Truncated Regressions

\begin{tabular}{|c|c|c|c|c|c|c|c|c|}
\hline & (1) & (2) & (3) & (4) & (5) & (6) & (7) & (8) \\
\hline Real GDP per capita PPP & $\begin{array}{c}0.000 * * * \\
(0.000)\end{array}$ & $\begin{array}{c}0.000 * * * \\
(0.000)\end{array}$ & $\begin{array}{c}0.000 * * * \\
(0.000)\end{array}$ & $\begin{array}{c}0.000 * * * \\
(0.000)\end{array}$ & $\begin{array}{c}0.000 \\
(0.000)\end{array}$ & $\begin{array}{c}0.000 * * \\
(0.000)\end{array}$ & $\begin{array}{c}0.000 * * * \\
(0.000)\end{array}$ & $\begin{array}{l}-0.000 \\
(0.000)\end{array}$ \\
\hline Rural population & & $\begin{array}{c}-0.014 * * * \\
(0.003)\end{array}$ & $\begin{array}{c}-0.013 * * * \\
(0.002)\end{array}$ & $\begin{array}{c}-0.011 * * * \\
(0.002)\end{array}$ & $\begin{array}{c}-0.010 * * * \\
(0.002)\end{array}$ & $\begin{array}{c}-0.014 * * * \\
(0.002)\end{array}$ & $\begin{array}{c}-0.008 * * * \\
(0.001)\end{array}$ & $\begin{array}{c}-0.006^{* * *} * \\
(0.001)\end{array}$ \\
\hline Population density & & & $\begin{array}{c}0.001 * * * \\
(0.000)\end{array}$ & $\begin{array}{c}0.000 * * * \\
(0.000)\end{array}$ & $\begin{array}{c}0.000 * * * \\
(0.000)\end{array}$ & $\begin{array}{c}0.001 * * * \\
(0.000)\end{array}$ & $\begin{array}{c}0.000 \\
(0.000)\end{array}$ & $\begin{array}{c}0.000^{* *} \\
(0.000)\end{array}$ \\
\hline Student-to-teacher ratio & & & & $\begin{array}{c}-0.014 * * * \\
(0.004)\end{array}$ & $\begin{array}{c}-0.014 * * * \\
(0.003)\end{array}$ & $\begin{array}{c}-0.015^{* * * *} \\
(0.004)\end{array}$ & $\begin{array}{l}-0.002 \\
(0.003)\end{array}$ & $\begin{array}{c}-0.005 * * * \\
(0.002)\end{array}$ \\
\hline Government effectiveness & & & & & $\begin{array}{c}0.203 * * * \\
(0.052)\end{array}$ & & & \\
\hline Wage bill (percent of total expenditure) & & & & & & $\begin{array}{c}0.005 \\
(0.003)\end{array}$ & & \\
\hline Gini coefficient & & & & & & & $\begin{array}{c}-0.008 * * * \\
(0.002)\end{array}$ & \\
\hline Adult literacy & & & & & & & & $\begin{array}{c}0.007 * * * \\
(0.002)\end{array}$ \\
\hline Constant & $\begin{array}{c}0.119 \\
(0.213)\end{array}$ & $\begin{array}{c}1.252 * * * \\
(0.193)\end{array}$ & $\begin{array}{c}1.202 * * * \\
(0.158)\end{array}$ & $\begin{array}{c}1.492 * * * \\
(0.171)\end{array}$ & $\begin{array}{c}1.488^{* * * *} \\
(0.148)\end{array}$ & $\begin{array}{c}1.429 * * * \\
(0.189)\end{array}$ & $\begin{array}{c}1.298 * * * \\
(0.169)\end{array}$ & $\begin{array}{c}0.459^{* *} * \\
(0.219)\end{array}$ \\
\hline Sigma & $\begin{array}{c}0.425^{* * *} * \\
(0.090)\end{array}$ & $\begin{array}{c}0.292 * * * \\
(0.036)\end{array}$ & $\begin{array}{c}0.265^{* * *} * \\
(0.029)\end{array}$ & $\begin{array}{c}0.228 * * * \\
(0.023)\end{array}$ & $\begin{array}{c}0.205^{* * *} * \\
(0.020)\end{array}$ & $\begin{array}{c}0.211 * * * \\
(0.024)\end{array}$ & $\begin{array}{c}0.150 * * * \\
(0.013)\end{array}$ & $\begin{array}{c}0.089 * * * \\
(0.011)\end{array}$ \\
\hline Countries & 76 & 76 & 76 & 69 & 67 & 51 & 43 & 39 \\
\hline Observations & 280 & 280 & 280 & 236 & 211 & 179 & 151 & 50 \\
\hline
\end{tabular}

Source: Author's calculations.

Notes: Standard errors are in parenthesis, ***,**,*, indicate statistical significance at the $1,5,10$ percent levels, respectively, sigma is the estimated standard error of the regressions.

\section{Conclusions}

We measure the efficiency of secondary education expenditure by adopting the hybrid approach developed by Wagstaff and Wang (2011). This allows us to take advantage of the strengths of DEA and SFA, while avoiding their weaknesses. As in the DEA, we identify efficient data points by relying on an envelopment process on a subsample of data points. At the same time, we allow for statistical noise by adopting the LOWESS method. Given that the efficiency scores are computed on the basis of observed data points from the sample, the approach avoids arbitrary assumptions on the functional form of the education production function.

We control for the level of development by splitting the sample into lower- and higher-income groups and estimate a hybrid frontier for each group, allowing the frontiers to be differently located and shaped. Then, we derive the efficiency scores by assessing the distance of data point to the closest point on the relative frontier. This should reduce the bias of having efficiency estimates affected by the level of development. We also introduce a modification to the original version of the hybrid approach by imposing an output orientation, which allows calculating the potential gains in terms of net enrollment at current spending levels. The latter is more suited for emerging and developing countries, where the main challenge is to improve educational outcomes, rather than reduce education spending.

The results suggest that education expenditure is inefficient in many emerging and developing economies, especially in Africa. We find that, on average, lower-income economies are less efficient than higher income ones. By eliminating inefficiency, lower income economies could raise the average net enrollment rate by 36 percentage points at current spending levels, compared with 7 percentage points in higher-income economies. The rankings are generally robust to different specifications.

These results are supported by a second stage analysis. In particular, reallocating expenditure to hire more teachers could improve the efficiency of public education spending where student-to-teacher ratios are high. Improving the quality of institutions would also have a positive effect on the efficiency of education spending. Finally, evidence suggests that easier access to public services (generally present in urban areas and areas with higher population density) makes education spending more efficient. One implication could be that complementary spending aimed at reducing the transaction and personal costs of attending school (e.g., investment in transportation) could have a spillover effect on the efficiency of education spending. In a similar vein, cash transfer programs could help reduce the opportunity costs 
of staying in school. This, in turn, could boost school enrollments and increase the efficiency of education spending. ${ }^{12}$

One noteworthy aspect of the results is that equity (in terms of income distribution) can be good for educational efficiency; countries with higher Gini coefficients tended to less efficient educational outcomes. This suggests that tax and expenditure policies that help reduce inequality can have a salutary effect on educational efficiency.

\section{Acknowledgements}

The views expressed herein are those of the authors and should not be attributed to the IMF, its Executive Board, or its management. I would like to thank Nazim Belhocine, Benedict Clements, David Coady, Sanjeev Gupta, Javier Kapsoli, Camelia Minoiu, Gerd Schwartz, Mauricio Soto, Adam Wagstaff, and the Bank of Thailand for their comments and suggestions. I am also grateful to the participants of an IMF seminar held in March 2013. Kanako Hotta and Lilla Nemeth provided excellent research assistance.

\section{Declaration}

The author agrees to cooperate with the Applied Economics and Finance in everything pertaining to the publication of the article in the journal. All rights not specifically mentioned herein are reserved by the IMF.

\section{References}

Almond, D., \& Currie, J. (2011). Human Capital Development Before Age Five. Handbook of Labor Economics, Elsevier.

Burgess, J. F. (2006). Productivity Analysis in Health Care. In: The Elgar Companion to Health Economics (ed). Cheltenham, UK and Northampton, Mass., Elgar.

Cleveland, W. S. (1979). Robust Locally Weighted Regression and Smoothing Scatterplots. Journal of the American Statistical Association 74: 829-36. http://dx.doi.org/10.1080/01621459.1979.10481038

Fiszbein, A., \& Schady N. (2009). Conditional Cash Transfers: Reducing Present and Future Poverty. (Washington: World Bank). http://dx.doi.org/10.1596/978-0-8213-7352-1

Gupta, S., Schwartz, G., Tareq, S., Allen, R., Adenauer, I., Fletcher, K., \& Last, D. (2007). Fiscal Management of Scale-Up Aid, IMF Working Paper No. 07/222 (Washington: International Monetary Fund). http://dx.doi.org/10.5089/9781451867862.001

Gupta, S., \& Marijn, V. (2001). The Efficiency of Government Expenditure. Experiences from Africa. Journal of Policy Modelling , 23, 433-67. http://dx.doi.org/10.1016/S0161-8938(00)00036-3

Greene, W. H. (2005). Efficiency of Public Spending in Developing Countries: A Stochastic Frontier Approach. World Bank.http://web.worldbank.org/WBSITE/EXTERNAL/TOPICS/EXTDEBTDEPT/0,,contentMDK:20297571 men uPK:4876071 pagePK:64166689 piPK:64166646 theSitePK:469043,00.html.

Grigoli, F., \& Ley, E. (2012). Quality of Government and Living Standards: Adjusting for the Efficiency of Public Spending. IMF Working Paper No. 12/182 (Washington: International Monetary Fund).

Herrera, S., \& Pang, G. (2005). Efficiency of Public Spending in Developing Countries: An Efficiency Frontier Approach. World Bank Policy Research Working Paper No. 3645 (Washington: World Bank).

Jayasuriya, R., \& Wodon, Q. (2003). Efficiency in Reaching the Millenium Development Goals. World Bank Working Paper No. 9 (Washington: World Bank).

Leuven, E., \& Sianesi, B. (2003). PSMATCH2: Stata module to perform full Mahalanobis and propensity score matching, common support graphing, and covariate imbalance testing. Boston College Department of Economics.

Verhoeven, M., Gunnarsson, V., \& Carcillo, S. (2007). Education and Health in G7 Countries: Achieving Better Outcomes with Less Spending. IMF Working Paper No. 07/263 (Washington: International Monetary Fund).

Wagstaff, A., \& Wang, L. C. (2011). A Hybrid Approach to Efficiency Measurement with Empirical Illustrations from Education and Health. Policy Research Working Paper No. 5751 (Washington: World Bank). http://dx.doi.org/10.1596/1813-9450-5751

World Bank. (2005). Specific Guidance for Education, Preparing PERs for Human Development, World Bank. Available at: http://www1.worldbank.org/publicsector/pe/PEAMMarch2005/PER-Education.pdf.

\section{$($ (c) $)$ EY}

This work is licensed under a Creative Commons Attribution 3.0 License.

${ }^{12}$ See Fiszbein et al. (2009) on the positive impact of conditional cash transfers on school enrollment and other educational outcomes. 